\title{
Cooperation under pressure: Time urgency and time perspective in social dilemmas
}

Renan Saraiva, Fabio Iglesias

\begin{abstract}
Social dilemmas typically require individuals to choose between a personal need or that of a group, often sacrificing one for the other. Many factors play a role in whether people choose to cooperate or to compete, but time constraint and other time-related variables might be decisive in this decision-making process. This study investigated the role of these time variables in individuals' choice to cooperate or compete, specifically by evaluating time pressure and the individuals' worldview of time (i.e., how they perceive and think about their present and future). Participants $(n=220)$ took part in ten rounds of a social dilemma task (the chicken game), either in a condition with time pressure or a control condition. Participants also completed the Zimbardo Time Perspective Inventory, and the Cooperative-Competitive Orientation Scale. As expected, rates of competition were higher in the experimental condition, where a 40 -second timer was set after the fifth round of the dilemma. In fact, more competitive behavior was observed with each successive round in the time-pressure condition, with the last round consistently being the most competitive. Present and future components of the time perspective variable were positively correlated
\end{abstract}


with competitive behavior, but only when under time pressure. No effect was found using the cooperation and competition attitudes measure. These results suggest that time pressure increases competitive behaviors, and that time perspective is related to competition only when there is an explicit time constraint in the decision process.

Keywords: Time pressure, Time Perspective, Social dilemma, Cooperation, Competition

\section{Introduction}

Many problems concerning interpersonal decisions, from the individual, group or international level, are based on situations in which people have the possibility to cooperate or compete. In some cases such decision process is bounded to a time constraint, so that choosing between cooperate or defect needs to be made relatively fast. A driver that is late for work and is facing a traffic jam, or a businessperson with tight deadlines to meet, exemplify situations in which individuals confront a crescent time pressure, occasionally being forced to make decisions faster. Would such individuals, experiencing a time pressure situation, be more competitive than others that do not have to hurry to make their decisions? Additionally, would differences between the way people think about their present and future be related to their cooperative and competitive attitudes? In this study we put these questions to test, in order to deeper understand the role of time-related variables in specific social interactions. 
Time constraints follow individuals in most phases of life, commonly raising worries and stress to those who claim being racing against the clock. Menzier (2005) argues that most people complain about not having enough time per day to do what they would like to do, and that they are working more and harder than ever. Such feelings can generate negative consequences, like stress and anxiety from a constant urgency in search for more time. Robinson and Godbey (1997) suggest that such an increase in the reports of time pressure could be explained by the changes in how the value of time was perceived along the years, such that a higher valorization of time seems to increase feelings of time pressure (DeVoe and Pfeffer, 2011).

\section{Time pressure}

Time pressure is commonly described as an urgency to finish a certain task or accomplish a certain goal, often generating feelings of anxiety, haste, and hurry (Szollos, 2009). This phenomenon, as a stressful variable, has many consequences in the judgment and decision-making processes of individuals, leading to changes in their affective states (Maule et al., 2000) and cognitive strategies (Ben Zur and Breznitz, 1981). Research shows that time pressure increases the speed of information processing (Ben Zur and Breznitz, 1981; Maule and Mackie, 1990; Payne et al., 1988) and decreases risky behaviors when expected consequences are positive, but increases engagement in risky behavior when 
expected consequences are negative (Busemeyer, 1985).

As an important decision process variable, this construct has been associated with a set of behaviors that involve the evaluation of costs and benefits of the action. The body of research in prosocial behavior can also shed light on the effects of time pressure on cooperation, given that both involve benefits to other individuals. Darley and Batson (1973), for example, found that time pressure greatly reduce prosocial behavior. Since the main goal of hasty individuals is to reduce time constraint, they pay little attention to other elements, such as individuals in need of help. Also, other manipulations of cognitive

loading, with effects similar to time pressure, reduce empathy (Davis et al., 1996). Despite the existence of this literature, however, the role of time pressure in situations where individuals have the possibility to cooperate or compete is still relatively unexplored

\section{Time perspective}

In addition to time pressure, another time-related variable that is broadly investigated in psychological studies is time perspective. According to the time perspective model, individuals differ in the way they perceive and think about their past, present, and future (Zimbardo and Boyd, 1999; Zimbardo and Boyd, 2008). The model describes five components of time perspective: Positive Past, Negative Past, Present Fatalist, Present Hedonist and Future. Those time perspective components have been related to risky 
behaviors (Zimbardo et al., 1997), social relationships (Lang and Carstensen, 2002), procrastination (Ferrari and Díaz-Morales, 2007), and preference for delayed rewards (Klineberg, 1968). Although the past components of time perspective are useful in explaining or predicting some behaviors and attitudes, such as depression, anxiety, unhappiness, low self-esteem and aggression (Zimbardo and Boyd, 1999), in this study they were not used. We made this decision because this component does not appear to have a direct relation with the other variables of this study, therefore only the present and future components of the scale were used here. The Present Hedonist component concerns an orientation to present pleasure, with hedonistic, risk-taking, or a "feel the moment" attitude towards time and life. The Present Fatalist involves a fatalistic and hopeless attitude toward future and life. Present oriented individuals have been found to be more prone to engage in risky behaviors (Zimbardo et al., 1997), to procrastinate activities (Ferrari and DíazMorales, 2007), and to develop pathological gambling behavior (Hodgins and Engel, 2002). Also, the present components have been positively associated with aggression, anxiety and ego undercontrol, and negatively associated with consideration of future consequences (Zimbardo and Boyd, 1999). Finally, the Future component regards an attitude focused on future events, characterized by goal achievement, planning and future rewards. This component has been associated with social goals (Lang and Carstensen, 2002), academic 
achievement (De Volder and Lens, 1982), preferences for delayed rewards (Klineberg, 1968) and higher rates of sustainable behavior (Corral-Verdugo et al., 2006).

Those studies provide some elucidation to how time pressure and time perspective would be related to cooperation, but is important to take into account that despite being similar, cooperation and prosociality show relevant differences (Penner, et al., 2005). In the decision-making process of cooperation, the individual needs to evaluate the odds that others involved in the situation will also cooperate, or otherwise compete. In such a scenario, competition is characterized as a risky behavior, because the outcome can be negative, if all the participants involved compete. Situations like these are often described in economic, social and psychological studies as social dilemmas (Dawes, 1980; Kollock, 1998).

\section{Social dilemmas}

Research that investigates cooperation and competition typically use social dilemmas as a methodological tool for accessing objective measures of such behaviors (Biel et al., 2008). Social dilemmas are situations of conflict between immediate selfinterest and long-term collective interests (Van Lange et al., 2013). The tragedy of the commons, a social dilemma proposed by Hardin (1968), illustrates a social dilemma with an ecological example. It involves a shared renewable resource, that can be easily depleted 
if users behave selfishly, taking a large part of the resource for themselves in a short period of time. Such a situation exemplifies a social dilemma because all participants need to collaborate in order to preserve the resource availability. However, there is always the possibility that some users will get a larger quantity of the resource within an everincreasing rate of consumption. There is, therefore, a need for a trust-based relation between those engaged in the dilemma.

In this study we chose to use the chicken game (Bornstein et al., 1997), referred sometimes as the snow-drift dilemma. Such dilemma offers two individuals the opportunity to cooperate or to defect, whereas the combination of their choices defines their outcomes. If both players cooperate, they receive a slightly positive outcome. If one defects while the other cooperates, the one defecting receives a larger reward than the one that cooperated. Finally, if both players defects, both receive the worst possible outcome. This situation reflects a social dilemma because defection is favorable when the other player cooperates, but such decision implies on a reduced overall pay-off for the group. We chose to use the chicken game instead of the most commonly used prisoner's dilemma (a similar dilemma, but with different outcomes proportions) because the former has higher cooperation rates (Doebeli and Hauert, 2005; Kümerlli et al., 2007). Thus, for the purposes of this study, it is a better approach to test the effects of time related variables on cooperation and 
competition.

A set of studies by Rand, Greene and Nowak (2012) found that time pressure increases cooperation rates in a social dilemma. However, their method was an one-shot public goods dilemma, where time pressure manipulation was the amount of time lapsed before participants made a decision (therefore, a more intuitive-based decision). In this study we propose a different manipulation of time pressure, offering participants a situation where time pressure increases continually, while observing its effects on cooperation. We expected that the frequency of cooperative behaviors would decrease as time pressure increases, given that time constraints often reduces prosocial behavior (Darley and Batson, 1973), while other cognitive load tasks reduce empathy (Davis et al., 1996).

\section{Hypotheses}

In this study we propose to verify the relations between time pressure and time perspective with cooperation and competition, both with behavioral (choices in the social dilemma) and attitudinal measures. A mixed experimental design was used to test four main hypotheses: a) Elevated rates of time pressure would increase rates of competition behavior in the social dilemma. b) Time perspective would be related to competition behavior in the social dilemma, with present-oriented individuals being more competitive than future-

oriented. c) Time perspective would be related to cooperation and competition attitudes, 
with present-oriented individuals presenting more competitive attitude than future-oriented. d) Cooperation and competition attitudes would also be related to cooperation and competition behaviors in the social dilemma.

\section{Method}

\section{Participants and procedure}

A sample of 230 Brazilian students (58\% female) participated in this experiment, of which 108 were from a large public university and 122 from two public high schools. We choose to get data from those distinct locations for both variability and convenience purposes. Participants' mean age was 18.5 years $(S D=4.22)$. They were arranged in 115 dyads, randomly allocated to one of two conditions: Time Pressure $(\mathrm{n}=58)$ and No-Time Pressure (control) ( $\mathrm{n}=57)$.

Participants were recruited personally or by phone, and asked to provide their consent. Both the social dilemma and the attitudinal measures were administered to all participants. In order to control for possible order effects, the presentation of the social dilemma and the attitudinal measures were counter-balanced. Each session lasted about 30 minutes. Participation in the study was voluntary and confidential.

\section{Social dilemma}

Cooperation and competition behaviors were measured by participants' decisions in 
a chicken-game dilemma. The outcomes in the dilemma were given in $\mathrm{R} \$ 1.00$, the Brazilian currency (approximately half a US dollar). However, participants were warned that they would not keep the money after the end of the experiment. The pay-off matrix was as follows: if both players cooperated they received two coins each; if one cooperated while the other competed, the one who cooperated received one coin and the one who competed received three coins; if both competed, both lost one coin (see Table 1).

Table 1. Pay-off matrix of the chicken game dilemma.

\begin{tabular}{|c|c|c|}
\cline { 2 - 3 } \multicolumn{1}{c|}{} & Player B cooperates & Player B competes \\
\hline \multirow{2}{*}{ Player A cooperates } & $\mathrm{A}+2$ & $\mathrm{~A}+1$ \\
& $\mathrm{~B}+2$ & $\mathrm{~B}+3$ \\
\hline Player A competes & $\mathrm{A}+3$ & $\mathrm{~A}-1$ \\
& $\mathrm{~B}+1$ & $\mathrm{~B}-1$ \\
\hline
\end{tabular}

A game instructor was responsible for coordinating the game, taking notes of players' moves and distributing pay-offs in coins after each interaction. A chart was used to 
show the pay-off matrix to the players, and to help explain the procedure. The game was played for ten rounds, while participants faced each other. For each interaction players had to indicate whether they wanted to cooperate or defect, by choosing a card to signal their choice. After each interaction the coordinator distributed the outcomes in coins to the players, according to the pay-off matrix.

In the Time Pressure condition a computer screen with a timer, which counted down the seconds left for the task, was placed near the participants. This was used to elicit an increasing feeling of time pressure in the dilemma. Before the game started, participants were told that the chronometer would eventually start its regressive count, signaling that they would have only 40 seconds left to play. The chronometer always started after the fifth interaction, but participants were unaware of when it would start. Only games that lasted ten interactions were considered for analysis. In the Control condition there was no chronometer and participants played all ten rounds normally. Therefore, only the last five rounds of the game differed between the two experimental conditions. To compare for differences between the Time Pressure and the Control conditions only data from the last five rounds was analyzed, since the time pressure manipulation started only in the fifth round and until there both conditions were completely similar. To other analysis not concerning time pressure we used all the interactions of the dilemma. 


\section{Attitudinal measures}

A Brazilian version (Milfont et al., 2008) of the Zimbardo Time Perspective Inventory - ZTPI (Zimbardo and Boyd, 1999; Sircova et al., 2014) was used to measure individual differences in time orientation. Items are accessed on a 5-point Likert scale, according to how characteristic a statement is for the respondent, ranging from 1 (very uncharacteristic) to 5 (very characteristic). Originally, it includes five components: positive past, negative past, present-hedonistic, present-fatalistic, and future. However, only present and future time orientations were used in this study. The Future component of the scale has 12 items $(\alpha=.74)$, such as "I complete projects on time by making steady progress". The Present-Hedonistic component has 11 items $(\alpha=.73)$, such as "I take risks to put excitement in my life". The Present-Fatalist component has nine items $(\alpha=.73)$, such as "My life path is controlled by forces I cannot influence".

An adapted version of the Cooperative-Competitive Orientation Scale (Stapel and Koomen, 2005), was used to obtain a measure of cooperation and competition attitudes of the participants. The scale has 11 items, including statements such as "It annoys me when other people perform better than I do". Each item is rated from 1 (very untrue/uncharacteristic) to 5 (very true/characteristic). A single component of the scale measuring Competition was used $(\alpha=.67)$. Participants also provided their demographic 
information at the end of the questionnaires.

\section{Results}

We began our analysis by testing the effects of administration order (first the social dilemma or the attitudinal measures) and sample location (university or high schools) as possible confounding variables. The hypotheses concerning time pressure, time perspective and competition were mainly tested through mean comparisons and correlational analysis. On each trial of the social dilemma, individual cooperative choices were scored as 1 and competitive choices were scored as 2 . An average of those choices was used as a competitive rate index. Table 2 summarizes the descriptive statistics for the sample.

Table 2. Descriptive statistics for competitive choices for total sample and by condition.

\begin{tabular}{lcccc}
\hline & $\begin{array}{c}\text { Age } \\
\text { Mean(SD) }\end{array}$ & $\begin{array}{c}\text { Competitive } \\
\text { choices - All } \\
\text { rounds } \\
\text { Mean (SD) }\end{array}$ & $\begin{array}{c}\text { Competitive } \\
\text { choices(rounds 1 to 5) } \\
\text { Mean (SD) }\end{array}$ & $\begin{array}{c}\text { Competitive choices } \\
\text { (rounds 6 to 10) } \\
\text { Mean (SD) }\end{array}$ \\
\hline All participants & $18.25(4.22)$ & $4.84(2.29)$ & $1.45(0.24)$ & $1.54(0.24)$ \\
$\begin{array}{l}\text { Control condition } \\
\begin{array}{l}\text { Time Pressure } \\
\text { condition }\end{array}\end{array}$ & $18.67(5.58)$ & $4.62(2.13)$ & $1.41(0.24)$ & $1.51(0.23)$ \\
\hline
\end{tabular}


The administration order did not affect competition rates in the social dilemma $(t=$ $0.25, p=0.80)$. Also, the order did not affect the competition attitudes scores $(t=1.04, p=$ $0.30)$ nor the Future and Present Hedonist components of the ZTPI $(t=0.79, p=0.23$ and $t$ $=1.21, p=0.43$, respectively). However, participants who first completed the attitudinal questionnaires showed higher scores in the Present Fatalist component of the ZTPI ( $t(228)$ $=4.00, p<0.001, r=0.25$ ), therefore this effect was controlled for in the subsequent analyses concerning this component. When compared to high school students, university students showed less competitive behavior in the dilemma $(t(228)=5.14, p<0.001, r=$ 0.32), lower scores in Present Fatalist component $(t(228)=7.94, p<0.001, r=0.46)$ and higher scores in Future component $(t(228)=1.81, p=0.07, r=0.11)$. Based on these results, sample location was also controlled for in subsequent analyses.

\section{Time pressure and competition}

Given that time pressure manipulation started only after the fifth round of the dilemma, only the last five interactions differed between the conditions. An analysis of these last interactions indicated that the frequency of competitive choices was higher in the Time Pressure condition when compared to the Control condition, $F(1,208)=6.76, p=$ $0.01, \eta_{\mathrm{p}}{ }^{2}=0.03$. Also, while evaluating the competitive rates in the last interaction of the 
game - when time pressure would be at the highest point - we found that in the Time Pressure condition the competition was even higher than in the Control condition, $F(1,208)$ $=7.94, p=0.005$ e $\eta_{\mathrm{p}}^{2}=0.04$.

\section{Attitudinal measures and competition}

Correlations between time perspective components and the rates of competition in the entire game were significant only for the Present Hedonist component $(r=0.12, p=$ 0.04). However, when analyzing these relationships in the experimental conditions separately, positive correlations were found in the Time Pressure condition for the Present Fatalist $(r=0.25, p=0.008)$, Present Hedonist $(r=0.18, p=0.04)$ and Future $(r=0.17, p=$ 0.05). In the Control condition only the relationship between Present Fatalist and competition rates was statistically significant $(r=-0.17, p=0.03)$. No significant correlations were found between the competition attitude measure and the time perspective components (smallest $p=0.18$ ). Finally, no relationship was found between the competition attitudes and competition behavior in the social dilemma $(p=0.24)$.

\section{Discussion}

We tested four hypotheses regarding the effects of time pressure and time perspective in competition and cooperation, both at behavioral and attitudinal levels: a) A time pressure 
situation would increase the likelihood of competition in a social dilemma; b) Individuals with higher Present Hedonist or Present Fatalist orientation would compete more in the social dilemma, while the more Future oriented would show less rates of competition; c) The Present Hedonist and Present Fatalist perspectives would be related to more competitive attitudes, while the Future perspective would be related to less competitive attitudes; d) The competition attitudes would be related to competitive behavior in a social dilemma.

Our findings suggest that when exposed to a time pressure situation, individuals facing a social dilemma assume a more competitive stance, which is maximized when time pressure is at higher levels. These results provide evidence that individuals are prone to compete more for a resource if access to such reward is compromised by a time constraint. Because individuals running against the clock focus on their own needs at the expense of others' needs (Darley and Batson, 1973), the observed outcome is less cooperation. Also, this result supports the findings that time pressure increases risky behavior when the expected values are negative (Busemeyer, 1985), given that competing in a social dilemma involves a risky decision. However, those results should be analyzed with caution, given the small effect size of our manipulation $\left(\eta_{\mathrm{p}}^{2}=0.04\right)$. Further studies using different cooperation and competition situations, as well as other time constraint manipulations are needed to further test this effect. 
We found significant relationships with competition rates and time perspective only under a time pressure situation. Such finding suggests that individual differences in time perspective only seem to influence competition in situations involving time constraints. As predicted, individuals that are more Present Fatalist and Present Hedonist oriented were more competitive in the social dilemma, supporting the evidence that these time perspectives are related to risky behavior (Zimbardo el al., 1997), to less commitment with sustainable behavior (Corral-Verdugo et al., 2006), as well as to little attention to future consequences (Zimbardo and Boyd, 1999). The present study adds that such substantial orientation to present, and little concern for future consequences, are also related to competition behavior.

In contrast to our second hypothesis, Future oriented individuals were also more competitive. This is a puzzling result, since future oriented individuals are more eager to choose for a long term and a big reward, in detriment for an immediate but smaller one (Klineberg, 1968; Zimbardo and Boyd, 1999). Such long term profit in a social dilemma is better reached by cooperating rather than competing (Doebeli and Hauert, 2005). It may be further hypothesized that future oriented individuals also compete more because such dimension per se is related to a greater search for feelings of accomplishment and fulfillment (De Volder and Lens, 1982), which can be achieved by competing more and maximizing consumption. Furthermore, this result may also be explained by the relation between future 
orientation and less procrastination, which would increase the tendency of future oriented individuals to maximize their welfare through competition (Brocas and Carrillo, 2001, Ferrari and Díaz-Morales, 2007).

The competition attitude measure was not related to any dimensions of time perspective nor with the competition behavior in the social dilemma. The absence of relations between attitudes and behaviors are recurrent in psychological studies, and the same apply to studies concerning competition in attitudinal and behavioral levels (Burton-Chellew and West, 2013), as well as in laboratory and real-case studies on social dilemmas (Van Lange el al., 2013). Still, the absence of relations between competition attitudes and dimensions of time perspective was an unexpected result. In any case, is relevant to point that the competition attitudes scale showed less than robust psychometric properties, which could mask any possible relations that real competition attitudes could have with other variables. The use (or construction) of better suited scales to measure competition attitudes is recommended. Also, we found appropriate psychometric properties in the Brazilian version of the ZTPI scale, adding further evidence for reliability to this adapted instrument (Milfont et al., 2008).

Further investigation on how time related factors affect cooperation and competition can be explored by including other variables and manipulations. A possible moderator of the 
effect between time pressure and competition rates is the value that individuals assign to time itself (DeVoe and Pfeffer, 2011). It is reasonable to predict that a higher valorization of time would imply in even higher competition rates in situations involving time constraints, but this has yet to be properly tested.

In sum, our study indicates that individuals are more eager to compete when under time pressure, and that time perspective slightly predicts competition in situations involving time. For example, when defining strategies in organizational contexts, one could recognize the role of time and time pressure for creating a more cooperative environment (Roe et al., 2009). In the production industry, time-based competition is needed when choosing among manufacturing products possibilities (Hum and Sim, 1996). Also, in the planning of transit policies is relevant to take into account how a time pressure context can increase competition behavior among pedestrians and drivers (Lucas and Heady, 2002). Furthermore, elucidating how time related variables are associated to cooperative and competitive behaviors can make a significant contribution to the literature on time management (Ulferts et al., 2013). As high levels of time pressure exist in virtually all realms of life (Menzier, 2005), this study opens several doors for potential application

\section{References}

Ben Zur H and Breznitz SJ (1981). The effect of time pressure on risky choice behavior. 
Acta Psychologica 47: 89-104.

Biel A, Eek D, Gärling T and Gustafsson M (2008) New issues and paradigms in research on social dilemmas. New York: Springer.

Bornstein G, Budescu D and Zamir S (1997) Cooperation in intergroup, n-person, and twoperson games of chicken. Journal of Conflict Resolution 41: 384-406.

Burton-Chellew MN and West SA (2013) Prosocial preferences do not explain human cooperation in public-goods games. Proceedings of the National Academy of Sciences 110(1): 216-221.

Busemeyer JR (1985) Decision making under uncertainty: A comparison of simple scalability, fixed sample, and sequential sampling models. Journal of Experimental Psychology: Learning, Memory, and Cognition 11:538-564.

Corral-Verdugo V, Sing BF and Pinheiro JQ (2006) Sustainable behavior and time perspective: Present, past, and future orientations and their relationship with water conservation behavior. Interamerican Journal of Psychology 40(2): 139-147.

Darley JM and Batson CD (1973) "From Jerusalem to Jericho": A study of situational and dispositional variables in helping behavior. Journal of Personality and Social Psychology 27(1): 100-108

Davis MH, Conklin, L, Smith A and Luce C (1996) Effects of perspective taking on the 
cognitive representation of persons: A merging of self and other. Journal of Personality and Social Psychology, 70(4): 713-726.

Dawes RM (1980). Social dilemmas. Annual Review of Psychology 31: 169-193.

DeVoe SE and Pfeffer J (2011) Time is tight: How higher economic value of time increases feelings of time pressure. Journal of Applied Psychology, 96(4): 665-676.

De Volder ML and Lens W (1982) Academic achievement and future time perspective as a cognitive- motivational concept. Journal of Personality and Social Psychology 42(3): $566-571$.

Doebeli M and Hauert C (2005) Models of cooperation on the prisoner's dilemma and the snowdrift dilemma. Ecology Letters, 8:748-766.

Ferrari JR and Días-Morales JF (2007) Procrastination: Different time orientations reflect different motives. Journal of Research in Personality 41: 707-715

Hardin G (1968) The tragedy of the commons. Science 162: 1243-1248.

Hodgins DC and Engel A (2002) Future time perspective in pathological gamblers. Journal of Nervous and Mental Disease 190: 775-780.

Hum SH, Sim HH (1994) Time-based competition: Literature review and implications for modelling. International Journal of Operations and Production Management 16: 7590. 
Klineberg SL (1968) Future time perspective and the preference for delayed reward. Journal of Personality and Social Psychology 8(3): 253-257.

Kollock P (1998). Social dilemmas: The anatomy of cooperation. Annual Review of Sociology, 24: 183-214.

Kümmerli R, Colliard C, Fiechter N, Petitpierre B, Russier F and Keller L (2007) Human cooperation in social dilemmas: Comparing the snowdrift game with the prisoner's dilemma. Proceedings of the Royal Society 274: 2965-2970.

Lang FR and Carstensen LL (2002) Time counts: Future time perspective, goals, and social relationships. Psychology and Aging 17(1): 125-139.

Lucas JL and Heady RB (2002) Flextime commuters and their divrer stress, feelings of time urgency, anb commute satisfaction. Journal of Business and Psychology, 16: 565-571.

Maule AJ, Hockey GR and Bdzola L (2000) Effects of time-pressure on decision-making under uncertainty: Changes in affective state and information processing strategy. Acta Psychologica 104: 283-301.

Maule AJ and Mackie P (1990) A componential investigation of the effects of deadlines on individual decision making. In: Borcherding K, Larichev and Messick DM (eds) Contemporary issues in decision making. Amsterdam: North-Holland. Menzier H (2005) No time: Stress and the crisis of modern life. Vancouver: Douglas and 
McIntyre.

Milfont TL, Andrade PR, Belo RP and Pessoa VS (2008) Testing Zimbardo Time Perspective Inventory in a Brazilian sample. Interamerican Journal of Psychology, 42(1): 49-58.

Payne JW, Bettman JR and Johnson EJ (1988) Adaptive strategy selection in decision making. Journal of Experimental Psychology: Learning, Memory and Cognition, 14: 534-552.

Penner LA, Dovidio JF, Piliavin, JA and Schroeder DA (2005) Prosocial behavior: Multilevel perspective. Annual Review of Psychology, 56:365-392.

Rand DG, Greene JD and Nowak MA (2012) Spontaneous giving and calculated greed. Nature, 489: 427-430.

Robinson JP and Godbey G (1997) Time for life: The surprising ways Americans use their time. Pennsylvania: The Pennsylvania State University.

Roe RA, Waller MJ and Clegg SR (2009) Time in organizational research. Routledge: New York.

Sircova A, van de Vijver FJ, Osin, E, Milfont TL, Fieulaine N, Kislali-Erginbilgic A, ... and Davydova I (2014) A global look at time: A 24-country study of the equivalence of the Zimbardo Time Perspective Inventory. SAGE Open 4(1): 1-12.

Stapel DA and Koomen W (2005) Cooperation, competition and the effects of others on me. 
Journal of Personality and Social Psychology, 88: 1029-1038.

Szollos A. (2009). Toward a psychology of cronic time pressure: Conceptual and methodological review. Time \& Society 18: 332-350.

Ulferts H, Korunka C and Kubicek B (2013) Acceleration in working life: An empirical test of a sociological framework. Time \& Society 22(2):161-185.

Van Lange PAM, Joireman J, Parks CD and Van Dijk E (2013) The psychology of social dilemmas: A review. Organizational Behavior and Decision Processes 120: 125-141.

Zimbardo PG, Keough KA and Boyd JN (1997) Present time perspective as a predictor of risky driving. Personal Individual Differences 23(6): 1007-1023.

Zimbardo PG and Boyd JN (1999) Putting time in perspective: A valid, reliable, individualdifferences metric. Journal of Personality and Social Psychology 77(6): 1271-1288.

Zimbardo P and Boyd J (2008) The time paradox. New York: Free Press. 